\title{
Remote-mount Actuation Control: A Veritable Solution to Unreliability of Anti-surge Control Valves in Gas Compressors
}

\author{
Haruna A. Ogweda and Joseph E. Okhaifoh
}

\begin{abstract}
This paper presents the design and implementation of a remotely mounted Anti-surge Control Valve (ASCV) for a mixed refrigerant gas compressor deployed in an industrial plant. The traditional ASCV model which is usually self-mounted is plagued by component failures due to stress fatigue from excessive vibrations leading to unreliability of the system. A new system with a remotemount actuation control system was developed, tested, installed and commissioned in place of the initial self-mount system. Test results showed that average percentage of trips caused by failure of the ASCV dropped from $70 \%$ with the initial set-up to $0 \%$ with the modified set-up. Hence, a lasting solution to the issue of component fatigue failure from vibrations has been resolved using the highly reliable developed remote-mount actuation control.
\end{abstract}

Keywords - Anti-surge control valve (ASCV), spill-back.

\section{INTRODUCTION}

In the gas industry there are gigantic compressors driven by huge turbines used for the compression of natural gas. These compressors could be axial or centrifugal and have huge vessels connected at their inlet as well as at their outlet. These compressors are critical, delicate, and expensive that great precautions are taken to protect them against damage or destruction. A major challenge faced while in operation is known as the "surge phenomena" whereby there is a reverse flow of process through the compressor. This can cause serious damage to the compressor internals which in turn leads to stoppage in production as well as very high financial implications for replacement [1].

Compressor surge can be prevented by installing a protection system known as a "spill-back valve" otherwise known as the Anti-surge Valve. Figure 1 shows the block diagram of a spill-back valve installed on a compressor. Antisurge Control Valves (ASCV) are special valves installed on compressors for the purpose of surge control. They have special configurations to meet the demands of the compressor in opening or closing in time to protect the compressor [2]. Like most other control valves, they require an actuation control system which is pneumatic driven to be able to operate. Basically, the actuation system of most anti-Surge valves is self-mount, this means the accessories or components for the actuation control of the valve are mounted

Submitted on December 02, 2021

Published on December 29, 2021.

Haruna A. Ogweda, Federal University of Petroleum Resources Effurun, Nigeria.

(e-mail: ogwedas2000@yahoo.com) on the actuator. This type of system is always associated with component breakdown from vibrations leading to low reliability.

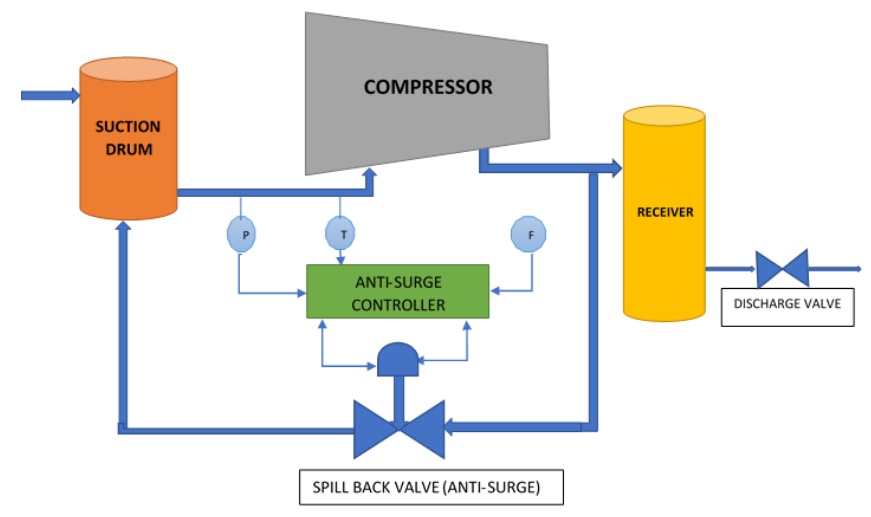

Fig. 1. Block diagram of an anti-surge valve installed on a compressor.

It is of great importance that these valves are always available on demand thereby ensuring high reliability. However, due to vibration induced failures, fatigue wear and tear of components on the valve actuation control, the selfmount system has become very unreliable and has been known to fail in responding accordingly when called upon by the compressor, thereby leading to compressor trip while in operation.

This work seeks to proffer a veritable solution to this failure associated with the self-mount ASCV. The root cause being excessive vibrations on the actuation system, leading to fatigue failures of components and consequently poor reliability. It involves modifying the traditional installation model of anti-surge valve actuation control system (selfmount) to a more rugged, compact, and maintenance friendly model (remote mount).

\section{REVIEW OF TRADItIONAL ASCV Model}

Like most other control valve, the traditional model of an anti-surge valve actuation control system is a self-mount system. By self-mount it implies that all the accessories and components of this system are mounted on the valve and actuator likewise, all the interconnections are done in-situ. Fig. 2 shows a pictorial view of a typical anti-surge valve system installed for a mixed refrigerant compressor at an

Joseph E. Okhaifoh, Electrical, Telecommunication and Computer Engineering Department, Kampala International University, Uganda. (e-mail: josephokhaifoh ${ }^{\circledR}$ kiu.ac.ug) 
Industrial Plant Complex in Bonny Island situated at Rivers State of Nigeria with coordinates: $4.4239^{\circ} \mathrm{N}, 7.2437^{\circ} \mathrm{E}$. The equipment specifications for the ASCV are:

ACTUATOR: $\quad$ Size -300 sq inch

Volume - 28 gallons i.e., 2310 cubic inch

Stroke -24 inches

Diameter -20 inches

Spring - none

Air action - close

Stroke time -10 s for control 1s for trip

VALVE:

$$
\begin{aligned}
& \text { Size }-30 \times 42 \text { inch } \\
& \text { Type }- \text { angle valve } \\
& \text { Rating }-300 \#
\end{aligned}
$$

eIn this model, the positioner is installed directly on the actuator and interconnected by means of small-bore tubing to the other accessories; the actuator itself is connected to the accessories by means of galvanized pipes and tubing making for a very rigid structure without consideration for the enormous vibrations experienced by the valve.

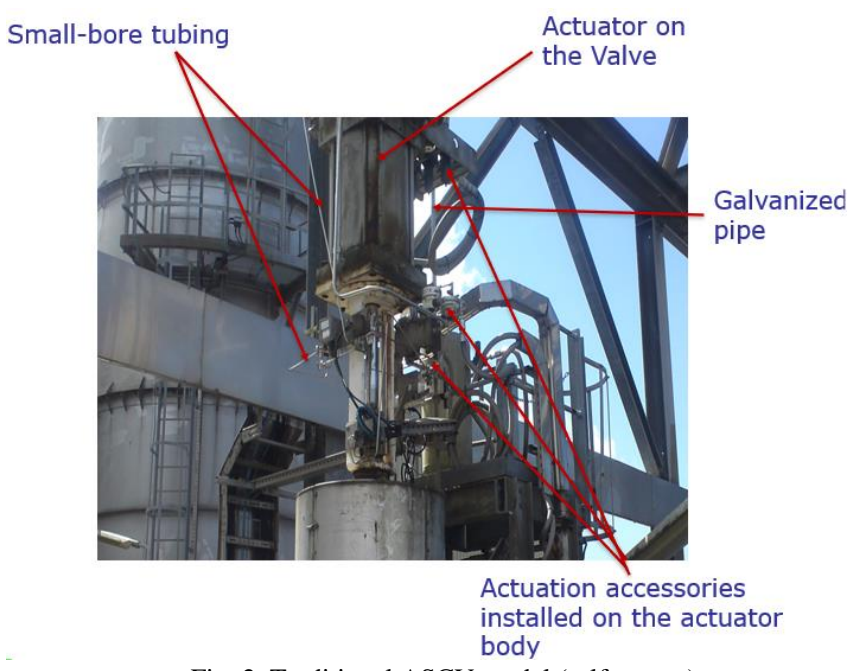

Fig. 2. Traditional ASCV model (self-mount).

Two major demerits are identified with this kind of installations particularly, because of the kind of service the anti-surge valve provides, these demerits are:

1) Vibration induced component failures due to the location of the valve actuation component on the process piping where the vibration is high

The ASCV based on this design have been plagued by component failures due to stress fatigue from excessive vibrations. By nature of its function the valve is connected to the compressor and conveys the content of the compressor being gas at a very high pressure, flow, and volume and as such, it is prone to excessive vibration. This vibration is transmitted to the accessories on the ASCV which are attached to the body of the valve and actuator. The rigid nature of the interconnection between the valve and accessories, means that the components are fatigued and over a short period of time they fail. Anytime a single component fails the anti-surge control valve goes to its fail-safe position which is a failure mode and consequently impacts its availability.
2) Small bore (Instrument) tubing snap and galvanized pipe fitting failure

Most of the interconnections between the positioner and other accessories are usually by means of small-bore tubing. These tubing even with the slightest dent and under vibration with time could snap.

Secondly, galvanized pipe fittings are used to connect bigger accessories like the volume flow boosters to the actuator itself. Galvanized pipes over time starts to rust and get weak, the zinc coating peels off due to weather conditions the valves are exposed to over time exposing the steel underneath to the atmosphere. These pipes are extremely difficult to work on during maintenance.

\section{RESEARCH METHODOLOGY}

The intent of this work is not to alter the production or output capacity of the ASCV but rather to improve on its reliability. Hence, the system's specification was deducted from the equipment data sheet and design calculations were done to ensure that those specifications were achieved. The control valve and actuator itself remain the same because obviously this cannot be changed however, in trying to tackle the issues of reliability the control mechanism needs remodelling which is the approach this work has taken. The control actuation system is so designed to achieve the name plate specification of the anti-surge valve.

Also, trip data culled from the historical record of the train trips for Self-mount setup from 2015 to 2019 were collected for analysis. Thereafter the Remote Mount system was designed, implemented and tested from January 2020 to June 2021.

\section{System Design of REMote MOUNT ASCV}

Although the vibrations experienced by the anti-surge valve cannot be totally eliminated since the process exists in the lines. However, the effects of the vibrations can be minimized to a minimum using the remote mount model. In this model all the accessories which are affected by vibration can be removed, assembled as a unit, and installed away from the actuator itself. This means they are no longer exposed to the vibrations experienced by the valve.

To achieve remote mount actuation control system two major questions must be answered if the accessories for control are to be installed away from the actuator:

1. How do we achieve the pneumatic connection between the remotely mount actuation control system and the valve actuator itself?

2. How will the positioner be installed to achieve position sensing and feedback remotely?

\section{A. Choice of Remote Mount Control}

This was achieved by installing all the components of the actuation system on a panel mounted on the Secure Instrument Air (SIA) vessel away from the vibrating valve and actuator. Connection will be achieved by means of a stainless-steel braided hose which is flexible and hence with minimal or zero vibration consequence. Fig. 3 shows the $1-$ inch stainless steel braided hose chosen for this design. 


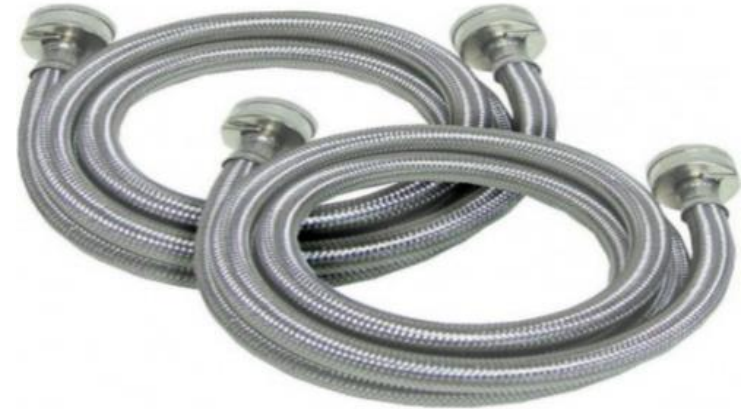

Fig. 3. 1-inch stainless steel braided hose.

The Self-mount model ASCV system uses the small-bore instrument tubing and galvanized pipe fittings for the interconnectivity of components. This has led to tensioned joined breaking off and pipes deteriorating under weather conditions. However, to solve these problems the $316 \mathrm{~L}$ stainless steel tubing with bigger bore and the stainless-steel braided hose is used. Stainless steel is corrosion resistant, and the braided hose helps to eliminate the effects of vibration because it is flexible and hence does not carry tensioned joints.

\section{B. Choice of Remote Mount Positioner (MD Series)}

The Flowserve Logix positioner is employed for the control of this valve. Contrary to the initial model that used self-mount positioner this modified system employs remote mount positioner. This is one of the major highlights of this model.

The Logix ${ }^{\circledR}$ Remote Mount option is intended for use where the positioner may be inaccessible when mounted to the valve/actuator package or when vibration or other operating factors may exceed the Logix ${ }^{\circledR}$ positioner recommended operating conditions. The Logix ${ }^{\circledR}$ remote mount option consists of two (2) components: The Logix ${ }^{\circledR}$ positioner configured for remote mount operation, and the remote feedback unit. The remote feedback unit must be wired to the $\operatorname{Logix}{ }^{\circledR}$ positioner following applicable standards for hazardous location installations [3].

It comprises of a feedback unit and the Logix positioner unit. The feedback unit is basically a potentiometer (remote mount module) fitted with a feedback and a follower arm, it is installed on the valve actuator itself and wired to the positioner which is installed remotely with other accessories of the ASCV. The actuator movement is transmitted to the feedback unit through the follower arm, the potentiometer responds accordingly and transmits its transduced signal to the positioner which takes appropriate action. This modified system effectively eliminates those effects of advanced vibration on the positioner. Fig. 4 shows a typical remote mount positioner and how it is connected remotely to an actuator.

\section{DESIGN IMPLEMENTATION}

In implementing this design, a direct approach was adopted. Fig. 5 shows the aassembled modified ASCV which is then tested and installed on site as seen in Fig. 6.

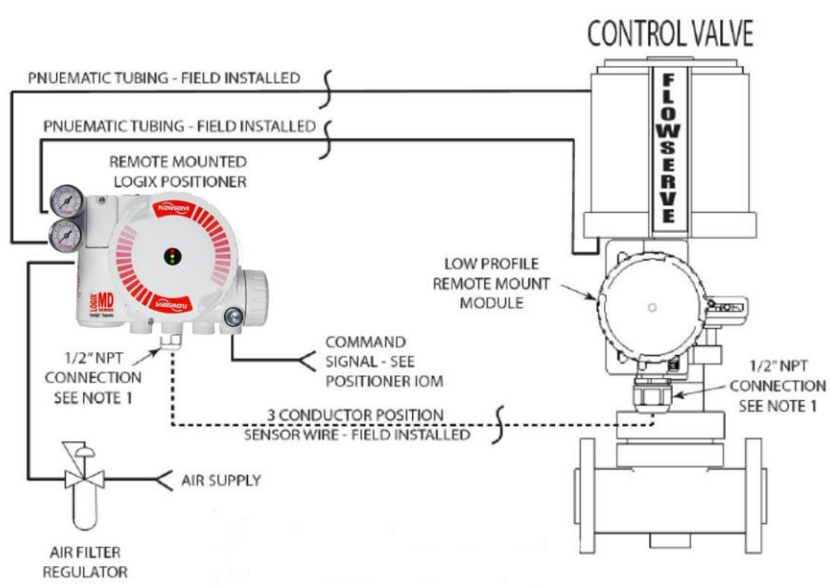

Fig. 4. Schematic of feedback unit module and Logix positioner [3].

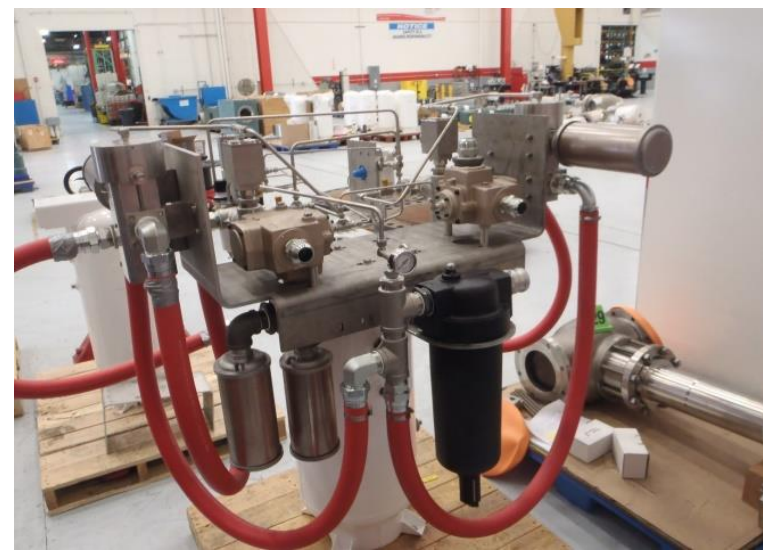

Fig. 5. Assembled Modified ASCV in the workshop.

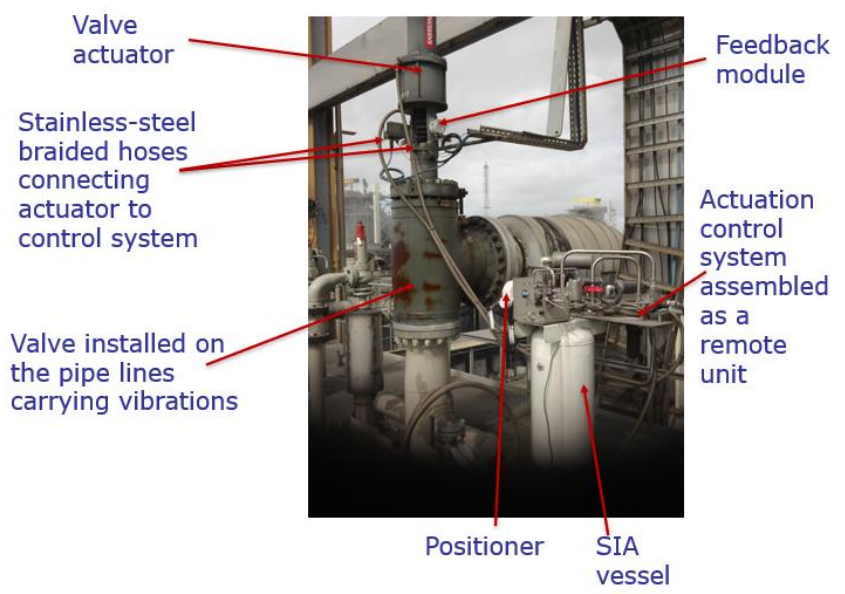

Fig. 6. Remote mount ASCV model.

\section{DATA PRESENTATION AND ANALYSIS}

A summary of the trip data culled from the historical record of the train trips for Self-mount and Remote mount systems are presented in Table I and Table II, respectively.

TABLE I: TRIP DATA FOR SELF-MOUNT ASCV

\begin{tabular}{ccccc}
\hline S/N & Year & $\begin{array}{c}\text { Total number } \\
\text { of trips }\end{array}$ & $\begin{array}{c}\text { Trips due to } \\
\text { ASCV failures }\end{array}$ & $\begin{array}{c}\text { \% of trips due to } \\
\text { ASCV failures }\end{array}$ \\
\hline 1 & 2015 & 6 & 5 & 83 \\
2 & 2016 & 8 & 4 & 50 \\
3 & 2017 & 6 & 4 & 67 \\
4 & 2018 & 7 & 5 & 71 \\
5 & 2019 & 5 & 4 & 80 \\
\hline
\end{tabular}

Mean failure due to ascv $=4.4$.

Average percentage trips due to ascv $=70$. 
TABLE II: TRIP DATA FOR REMOTE-MOUNT ASCV

\begin{tabular}{ccccc}
\multicolumn{4}{c}{ TABLE II: TRIP DATA FOR REMOTE-MOUNT ASCV } \\
\hline S/N & Year & $\begin{array}{c}\text { Total } \\
\text { number of } \\
\text { trips }\end{array}$ & $\begin{array}{c}\text { Trips due to } \\
\text { ASCV } \\
\text { failures }\end{array}$ & $\begin{array}{c}\% \text { of trips due } \\
\text { to ASCV } \\
\text { failures }\end{array}$ \\
\hline 1 & 2020 & 5 & 0 & 0 \\
2 & 2021 & 2 & 0 & 0 \\
\hline
\end{tabular}

Mean failure due to ASCV $=0$.

Table I shows the number of train trips recorded over a five-year period from 2015 to 2019, this represents the period when the Self-mount ASCV was in use whereas Table II shows the trip data from 2020 to 2021, this represents the Remote-mount set-up period. The average percentage of trips caused by failure of the ASCV drops from $70 \%$ with the initial set-up to $0 \%$ with the modified set-up. It is worthy of note here that the total trips recorded is a combination of trips due to ASCV failure and trips due to other factors like human error, electrical failure etc. However, it will be observed that the trips due to ASCV failure form the bulk of the total trips this necessitated the need for a solution and hence this work. From the time this work was commissioned in 2020 it will be observed from Table II that no trips due to ASCV failure have been recorded., This further proves that this work has met its objectives. However, the total number of trips for 2020 is still relatively high, this is because of the peculiarity of the year 2020 with respect to the novel Covid-19 virus which had an adverse effect on manning of the plant. "Working from home" was introduced and as such the plant could not be adequately manned this resulted to a lot of trips due to "other" factors particularly human errors.

\section{CONCLUSION}

Field instrumentation in a process plant deals with pressures and flow, these phenomena produce a lot of vibrations in equipment which over time lead to failures due to equipment fatigues. This work has helped to identify potential solution to vibration related issues on instruments particularly control valves. It has shown how the actuation and control of large valves with considerable vibrations can be achieved. By remote mounted control module, we can curb the effects of vibration on this kind of systems consequently improving their reliability.

\section{ACKNOWLEDGMENT}

The authors wish to acknowledge and appreciate the staff and management of Nigeria Liquified Natural Gas Limited for their support during this work.

\section{REFERENCES}

[1] M. P. Boyce, Gas Turbine Engineering Handbook, $4^{\text {th }}$ ed. Waltham, MA: Elsevier, 2012, pp. 283-292.

[2] G. Ali and G. Ghazanfarihashemi. Protecting a centrifugal compressor from surge. Pipeline \& Gas Journal, March 2012; 239(3).

[3] Flowserve Corporation. Remote mounting. Utah, U.S. Project 70005409, October 2014.

[4] V. Dimitios and P. George. Industrial compressor anti-surge computer control. Proceedings of World Academy of Science, Engineering and Technology, August 2007; 23:339-342.

[5] A. Continovis, D. Pareschi, M. Mercangoez and T. Basselmann. Model predictive anti-surge control of centrifugal compressors with variablespeed drives. Proceedings of the 2012 IFAC Workshop on Automatic
Control in Offshore Oil and Gas Production, Norwegian University of Science and Technology, Norway, 2012.

[6] A. A. Amin and K. Mahmood-Ul-Hasan. Advanced anti-surge control algorithm for turbine driven centrifugal compressors. Department of Electrical Engineering, University of Engineering and Technology, Lahore, 2015. 27(3): 1845-11854.

[7] W. Jacobson, M. Zaghloul, M. Tolmatsky, S. Staroselsky, and J. McWhirter. Compressor load sharing control and surge detection techniques. presented at the $45^{\text {th }}$ Turbomachinery and $32^{\text {nd }}$ Pump Symposia, Houston, TX, September 12-15, 2016.

[8] P. Aaslid. Modelling of variable speed centrifugal compressors for antisurge control. M.S. thesis, Dept. Eng. Cybernetics, Norwegian University of Science and Technology, 2009.

[9] T. L. Kumar and A. Swati. (March 2016). Anti-surge control software using general purpose programmable single loop controller. Research Journal of Engineering Sciences. [Online]. 5(3). pp. 49-52. Available: http://www.isca.in

[10] A. Kuzmichev. (June 2012). Compressor surge prevention control implemented on Yokogawa Stardom. The Next Generation of Control Technology. [Online]. SPC/STSC ON YOKOGAWA.

STARDOM E.001.120607. Available: http:// www.ccsia.com. 